\title{
Public's Trade-off between a New Risk-based Airport Screening and Asserted Terror Risk Impact: A Stated Choice Survey from Norway
}

\author{
Knut Veisten, Stefan Flügel, Torkel Bjørnskau \\ Institute of Transport Economics (TØI), Oslo, Norway \\ E-mail: $\{k v e, s f l, t b j\} @$ toi.no \\ Received February 18, 2011; revised March 22, 2011; accepted March 29, 2011
}

\begin{abstract}
This paper presents a survey-based economic evaluation of security measures protecting against the risk of aviation terrorism. A sample of Norwegians were asked to state their choices between different air travel alternatives, i.e. travel time, trip costs, fatalities in terrorist acts on air transport and type of passenger screening. Screening was specified as either the current uniform screening or a new risk-based screening in which passengers are divided into three groups: high-risk, medium-risk and low-risk. Respondents were informed that risk-based screening implied they would have to identify themselves using a biometric identity card and that those not qualifying as low-risk passengers would be checked with body scanners. Our results indicate that the sampled passengers were very concerned about privacy. Maintaining existing uniform screening was preferred to a new risk-based screening system, even though risk-based screening was presented as potentially preventing future terrorist fatalities.
\end{abstract}

Keywords: Biometric Identity Card, Body Scanning, Privacy, Value of Statistical Life

\section{Introduction}

Over the past few decades there has been a tightening-up in the control of air passengers and of their checked-in luggage, with a particular escalation since September 11, 2011 [1-3]. Stricter security control has increased security costs at airports and has meant more egress time for passengers [4-6]. The rationale for this development is based on assumed increased terrorism and that attacks are prevented by the airport screening [7]. The airport authorities in Norway have followed-up on the tightening of air passenger screening, although there is no history of terrorist attacks on Norwegian aviation [8]. In international aviation, all passengers are now subject to more or less identical security screening procedures, i.e. everybody is considered a potential threat [9]. The current uniform screening regime is costly and has a negative impact on all passengers, however, and the considerable resources allocated to checking harmless individuals are a source of inconvenience and delay [3].

A risk-based airport security policy represents a potentially cost-reducing selective screening regime [10]. In risk-based airport screening, also termed "positive pas- senger profiling", most passengers pre-qualify for different screening levels. The well-functioning of this prescreening system is a decisive assumption that the probability of a successful terrorist attack is reduced [9]. Frequent flyers can register with a biometric identity card, and if they have a clean record they normally qualify as "low-risk passengers" [3]. When recognised from fingerprint, iris and/or face, they would pass through express lanes at checkpoints with no shedding of garments and no control of hand luggage. A few would be randomly tested with "ordinary passengers", facing a screening similar to the current level, but possibly involving body scanning (backscatter X-ray technologies). The "highrisk" passengers would either be among the unknown or on a watch list. They would pass through body scanning and both their checked-in luggage and carry-on baggage would be subjected to explosive detection inspection $[10,11] .{ }^{1}$

${ }^{1}$ In the US, a computer-aided passenger pre-screening system implemented in 1998 separates passengers not representing a risk (non-selectees) from those who cannot be cleared of being a risk (selectees); the latter are subjected to more scrutiny than the other passengers [9]. Thus, some attempted identification of "high-risk" passengers is already implemented. 
Reduced security management costs and reduced egress time for passengers are the main arguments for a change to risk-based screening. A reduction of the current expected egress time (per passenger and luggage) from nearly $20 \mathrm{~min}$ to just $2 \mathrm{~min}$ is proposed for "low- risk" passengers. Ordinary passengers, too, would have their egress time reduced if a proportion of "low-risk" passengers were removed from screening, presumed to be about $13 \mathrm{~min}$ [3]. Reduced egress time is obviously valued by passengers. A change to risk-based screening reducing the risk of terrorism (the probability of successful terrorist attacks on air transport) would have an impact that passengers would value in monetary terms [12]. The impact on security from a change to risk-based screening is not obvious, however [9,13]. Furthermore, profiling based on personal data (biometric cards) and possible use of body scanning might be considered intrusive $[7,14]$. Risk-based screening could also be a violation of human rights if, for example, ethnicity and/or religion were mixed in with profiling [15]. Even disregarding legal issues, a risk-based screening regime might not be preferable to the current uniform screening regime.

In this paper, we present a choice experiment where a sample of the Norwegian population chose between hypothetical alternatives that differed in security regime, time-use, cost and impact on expected number of fatalities resulting from terrorism. Our application is a "bottom-up" risk assessment based on citizens' stated preferences compared to the common "top-down" risk assessment matching "vulnerability and threat against investment of resources" [16]. To our knowledge, one similar choice experiment applied to rail travel in the UK [17] and another type of choice experiment applied to air travel in the US [18] have been published.

The remainder of this paper is organised as follows. The next section briefly describes the economics of terror, the approach to measuring terrorist risk changes and the modelling framework for choice experiments. The third section specifies the particular scenario, including the range of risks, or fatality changes, considered by the respondents. Section 4 presents the survey data and section 5 the results of the choice modelling. Results are given and conclusions drawn in the last section.

\section{Theory and Methods}

In our study, the issue at stake is the monetisation of benefits from defending against terrorism, assuming that a particular defence measure, an averting action, will reduce the probability and/or the consequences of a terrorist attack [19]. The impacts of "successful" terrorist attacks have differed greatly, but one major di- rect impact has been the killing and injuring of people $[3,20]$. The monetisation of benefits from measures that can prevent attacks will, accordingly, comprise the value of statistical lives [21,22]. ${ }^{2}$ However, measures attempting to curb terrorist risk may also have additional positive and negative effects $[23,24]$. E.g., countermeasures can reduce ordinary crime such as vandalism, theft/robbery and assault. The potential negative effect is that surveillance and security screening are considered intrusive by some citizens, and that some might be willing to pay to avoid it $[7,13]$. A change from the current uniform passenger screening to risk-based screening could be a further step confronting civil liberties. Body scanning can be considered as a directly intrusive measure, and the recording of biometric data involves the potential peril of coupling with data which could hamper privacy and anonymity [14,25].

In the economics approach to the selection of type and degree of control and enforcement, the goal is to estimate or design some optimal level [26]. In applying a costbenefit assessment, the type and degree of control that maximizes net benefits, or the benefit-cost ratio, has to be selected. A pertinent question is then the degree to which all effects can be valued in monetary terms. While the costs of the measures relate to resources and labour that have some market-based price reflecting opportunity costs, the impacts on attack probability and its potential consequences are not readily gauged from market information. We limit the scope of impacts from terror to fatalities in attacks (terror fatality risk) and assume that this risk might be influenced by the type of passenger screening. Disregarding more enduring indirect effects from terror on transport and economic activity [12,23,24], simplifies the analysis. But even for such a partial approach there are several challenges with respect to economic valuation, applying stated choice methodology to include impacts not valued in markets, together with the ordinary costs of the security measures [17].

The results of a stated choice survey can be analysed by logit models [27]. In simple standard binomial/multinomial logit modelling, the ratio of any impact over cost yields a valuation of that impact (a "part-worth") if an underlying linear utility function is assumed. This standard logit model is based on the assumptions that all choice probabilities are independent of the presence of irrelevant alternatives (IIA) and the errors (the random and unobserved part of the indirect utility) are Gumbel-distri-

\footnotetext{
${ }^{2}$ Terrorism has broader economic impacts than killing and injuring people. In terrorist attacks on the transport system, infrastructure might be destroyed and route choice or transport mode choice altered. Changes like this may even persist after the infrastructure is rebuilt $[6,23]$. The fear that terrorism can indirectly affect various economic activities, such as tourism, foreign investments and trade and local/regional economic development, can be suppressed $[12,24]$.
} 
buted [28,29]. The probability (Pr) of individual $n$ choosing alternative $k\left(y_{n}=1\right)$ rather than alternative $l\left(y_{n}=0\right)$ in a standard binomial logit:

$$
\operatorname{Pr}\left(y_{n}=1\right)=1 /\left(1+\exp \left(V_{n l}-V_{n k}\right)\right)
$$

where $y_{n}$ is individual $n$ 's choice between the two alternatives, $V$ is the systematic (observable) part of the (indirect) utility and $e$ is the exponential function. Equation 1 implies constant error variance, which is usually assumed in logit models. The linear-in-para-meters utility, $V$, of the alternative chosen, $j=k, l$, can be stated as:

$$
V_{n j}=\beta_{0}+\beta_{1} X_{n j 1}+\cdots+\beta_{M} X_{n j M}
$$

where $\beta_{m}, m=0, \cdots, M$ are the $m+1$ unknown parameters to be estimated, while $X_{m}, m=1, \cdots, M$ are the $M$ explanatory variables in the model.

One of the $m$ parameters in our model refers to terrorist risk. Since Norway has no history of terror attacks, future risk estimates must be based on common international or European figures. An annual risk estimate of $8.63 * 10^{-6}$ for Norwegian aviation, in the period after September 11, 2011 has been presented [8]. In regard to risk presentation, it has been proposed the use of fatality numbers rather than risk figures in stated choice [30]. The above-mentioned risk figure would yield an expected 0.0345 fatalities per year, i.e. slightly less than one fatality over a 25 -year period.

The ratio of the terrorist fatality parameter (say, $\left.\beta_{3}\right)$ over the cost parameter (say, $\beta_{1}$ ) will yield the monetized part-worth, per air travel, of reducing the number of terrorist fatalities by one. Applying the induced terrorist risk in the stated choice experiment, we can estimate the implicit value of a statistical life (VSL) in an aviation terrorist context. ${ }^{3}$ Thus, we divide the monetized partworth of terrorist fatality reduction by the terrorist fatality risk $(p)$ :

$$
\mathrm{VSL}=\beta_{3} /\left(p \beta_{1}\right)
$$

When respondents in a stated choice survey are asked to choose between alternatives with different fatality levels, rather than fatality risk levels, it is implicitly assumed that they behave as if they consider risk levels, since (objective) risk levels are applied for estimating VSL [31]. ${ }^{4}$ Likewise, the ratio of the time parameter (say, $\beta_{4}$ ) over the cost parameter $\left(\beta_{1}\right)$ yields an estimate of the value of travel time savings (VTTS):

$$
\mathrm{VTTS}=\beta_{4} / \beta_{1}
$$

\footnotetext{
${ }^{3} \mathrm{VSL}$ is defined (approximately) as the amount that people are willing to pay for a reduction of fatality risk in the expectation of saving one life, a population mean of the marginal rate of substitution between wealth and mortality risk [21].

${ }^{4}$ This problem in the use of fatalities instead of fatality risk resembles the problem of the behavioural assumptions in revealed preference methods like hedonic pricing $[32,33]$.
}

Finally, the new proposed selective risk-based screening control can be valued by the ratio of its dummy parameter (say, $\beta_{2}$ ) over the cost parameter $\left(\beta_{1}\right)$ :

$$
\text { Value of risk-based screening }=\beta_{2} / \beta_{1}
$$

\section{The Data}

In April 2009 an internet-based questionnaire ready for pilot testing was structured as follows:

1) Introduction to the issue of fatality risk and numbers, caused by accidents or terror.

2) Policy scenario for change (reduction) in expected terror fatality numbers, introducing a new risk-based passenger screening.

3) Presentation of expected impacts on fatalities, timeuse and costs from a change to risk-based passenger screening.

4) Six pair-wise choices (plus an "opt-out") between travel alternatives with different levels on the attributes screening type, fatalities, time-use and costs.

5) Questions about attention to the attributes in the choices.

6) Income and other individual characteristics.

Fourteen individuals responded to the pilot survey, ${ }^{5}$ and based on their answers, the attribute balance in the stated choice experiment was found acceptable. However, the introduction to the terror risk and risk-based screening type presentation was simplified.

The main survey was carried out in June and July 2009, with respondents recruited from the largest internet panel in Norway (http://www.synovate.com/about/where/europe/norway.html). The full sample comprised 472 complete answers. After deleting respondents always choosing either the left-hand or the right-hand side alternative ("side-lexicographic answering") or only opting out ("don't know"), 432 respondents were considered for analysis of the stated choices. The young and the elderly are underrepresented in our panel sample compared to figures for the Norwegian population. Furthermore, our panel sample has higher income levels than the overall population [34]. ${ }^{6}$ The sample was introduced to a new risk-based security control at airports, as shown in Textbox 1.

After presentation of the risk-based security control, the respondents were introduced to a choice experiment

\footnotetext{
${ }^{5}$ However, in the pilot the respondents faced a choice experiment related to rail transport, but with the same attributes as for the air transport main survey.

${ }^{6}$ According to Synovate Norway (www.synovate.no), our response rate is common for their internet panel, and they apply techniques to adjust the sample to population figures, i.e. distributions of gender, age and regional appurtenance. The panel members had been recruited through a two-step process involving a telephone interview and an internetbased survey. Synovate Norway, formerly MMI (Markeds-og Mediainstituttet) $A S$, is part of the international opinion research company Synovate (www.synovate.com)
} 


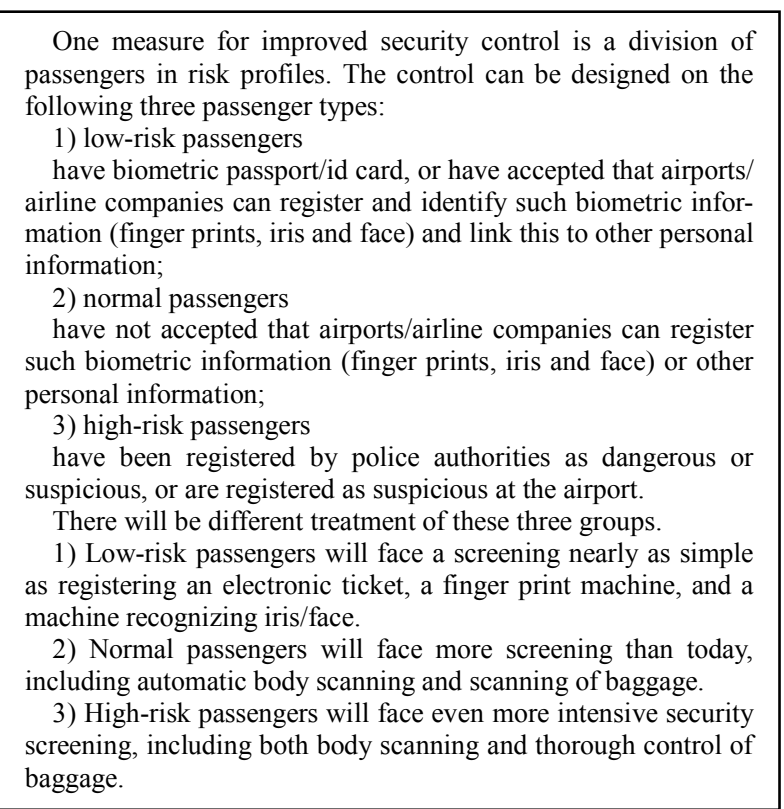

Textbox 1. Scenario - new risk-based security control at airports.

scenario, as displayed in Textbox 2.

As indicated, the choice experiment included four alternatives. Each respondent faced six choices, where the two alternatives differed in levels of

1) the (expected) number of people killed in terrorist attacks on air transport in Norway in the next 25 years,

2) the travel cost for a trip by air of a given length,

3) the travel time for a trip by air of a given length, ${ }^{7}$ and

4) the type of security control.

The type of security control had just two levels existing uniform control (dummy equal zero) and new risk-based control-including biometric registrations and body scanning of high-risk passengers. The other three attributes had five levels for each respondent, one base level with two levels up and two down. The base level given for the number of people killed in terrorist attacks on air trans- port in Norway was 15 over the next 25 years; the two levels below were 5 and 10 and the two above 20 and 25 . These levels are relatively high compared to existing terror risk estimates $[8,35,36] .{ }^{8}$ Figure 1 displays the structure of the pair-wise choice with the four attributes, as applied in the choice experiment.

In this format, a "don't know" response would open a pop-up window with three response alternatives:

1) "I think $k$ and $l$ are nearly equivalent"

2) "Neither $k$ nor $l$ are relevant to me"

3) "Other"/"No response"

This provides an "opt-out" alternative for the respondents. According to previous choice experiment research, forcing respondents to choose between irrelevant options
Security control at airports based on such a division of passengers into low-risk passengers, normal passengers, and high-risk passengers may yield changes

1) in ticket costs (since reconstruction of airports may yield higher or lower costs)

2) in travel time (which is particularly due to the belonging in one of the three passenger groups), and

3 ) in the risk of fatalities from terror against airplanes.

We will now present two airplane trip alternatives $A$ and $B$ at the screen. The cost, the total travel time, the expected number of perished in airplane accidents or terror against airplanes in Norway, during the next 25 years, and type of security control (based on risk profile or as it is currently), will differ between the alternatives.

Remember that increased travel time and increased costs reduce your possibilities for other activities and other consumption.

We ask you to consider carefully each alternative before you make your choice.

Textbox 2. Scenario - experimental choice involving type of security control, terror fatalities, time-use and cost.

is not recommended [27]. However, "don't know" choices were not included in the logit analysis; the choices are analysed as pair-wise choices.

Different hypothetical reference levels were allocated to the respondent for the attributes travel time and travel costs. While the hypothetical flight time varied between approximately 80 and 600 minutes, the hypothetical cost varied between approximately NOK 100 and NOK 7,500 (that is, EUR 11 - EUR 830). Since the base levels varied between respondents, so also did the changes (i.e. the two levels below and the two above).

The six pair-wise choices from the respondents are analysed using a standard logit model, the results indicating how much a change in an attribute (travel time, travel cost, terrorist fatalities or type of screening control) would affect the utility of an alternative, and thus its

\footnotetext{
${ }^{7}$ The base time for air was defined from arriving at the airport of departure until leaving the destination airport. This was considered a reasonable measure of travel time, as reducing time-use in the air was not deemed feasible. In our context it was important that the trade-off should include security screening time. We stress that our respondents were assigned to combinations of travel costs and travel times defined from other respondents' reported travels. Our intention was to pivot the choice experiment in our survey to the respondents' reported actual travel behaviour that they had reported in a first wave survey prior to our (second wave) survey [34]. Unfortunately, the correct linkage could not be established, such that the air travel choice experiment in our survey was responded to by people who had not necessarily described air travel in the first wave. Thus, our choice experiment is most likely perceived as purely hypothetical.

${ }^{8}$ The implicit terrorist risk levels in our choice experiment, from 0.2 to 1 killed per year, might be considered as relatively high in relation to the historic level for Norway, which is zero, and the populationweighted average level for transport in Europe, which would yield an annual risk of 0.03278 for Norwegian transport $[8,35,36]$. If we relate the baseline level of 0.6 killed per year to potential terrorism at the main airport of Oslo (OSL Gardermoen), with 20 million trips per year, the baseline risk level is 3 in 100 million. This is about three times higher than the estimated risk level in US air transport from 1970 to 2000, but far lower than the estimated post-2001 risk level [7].
} 


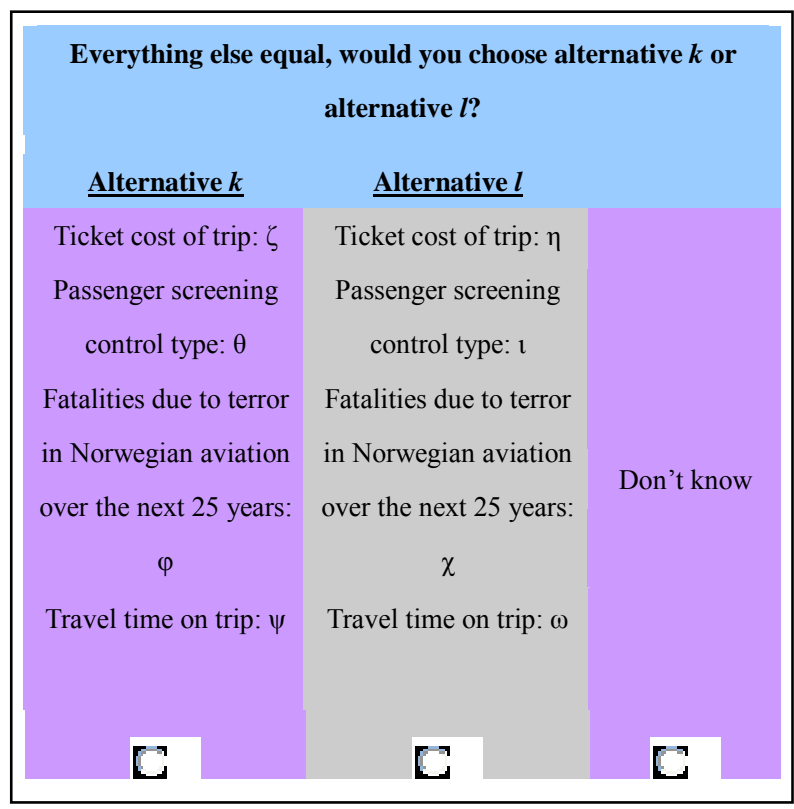

Figure 1. The (pair-wise) format of the choice experiment with four attributes.

probability of being chosen. The parameters estimated in the logit model will enter the value estimates.

\section{Results}

\subsection{Descriptive Analysis}

We have reported individual characteristics from only 366 of the 432 respondents. They seem adequately representative of an adult sample of the Norwegian population, considering age, gender and income, while the share reporting higher education is above population averages. The respondents' ages range from 18 to 77 with a mean of 45 years. The female share in our sample is 48 per cent. Close to 60 percent report receiving a net income of between 10,000 and 30,000 NOK monthly and 69 percent hold a university degree or equivalent.

Before the choice experiment, the respondents were asked what risk group they believed they would be classified within-their responses ranged as follows: 58.6 per cent low-risk, 41 percent normal and 0.4 percent highrisk. They were also asked about their perception of terrorist risk versus accident risk when flying; 46.7 percent ticked the response alternative indicating that they did not consider any of the risks when flying, while 35.4 stated that they thought about accident risk only. Merely 0.7 per cent stated that they thought only about terrorist risk; however, 15.7 percent ticked the response alternative indicating that they thought about both types of risk when flying (1.5 percent ticked "don't know"). They were also asked if they believed that current passenger screening control at Norwegian airports prevented terror, and responses were given on a scale from 1 "not at all" to 7 "to a very large extent". About 25 percent ticked 5, while about 20 percent ticked 4 ; the weighted average was $4.2{ }^{9}$

\subsection{Statistical Analysis}

Altogether in the six pair-wise choices there are 2,439 valid choices $(1,222$ of the left-hand side alternative and 1,217 of the right-hand side, i.e. alternative $k$ and alternative $l$ in Figure 1). In addition, 123 opt-outs can be considered as low. ${ }^{10}$ The four attributes were quite well balanced, but there was a tendency among some to choose the alternatives with current security control type and lowest level of killed in terrorist attacks on aviation. The following table summarizes this choice behaviour.

The share of respondents with lexicographical preferences, i.e. those who always (within the 6 choices) chose some alternative with best level of one particular attribute, was as follows: 10.4 percent the alternative with current screening type, 4.1 percent the alternative with new risk-based screening, 22.4 percent the most secure (lowest fatality) alternative, 3.4 percent the faster alternative and, finally, 4.1 percent the cheaper alternative.

There are various ways of modelling the observed choices, and we present three models focusing on the assessment of preference for risk-based screening. The first is a standard (binomial) logit model; the second is also a standard logit model but the preference for risk-based screening is linked to the respondent's self assignment to expected risk-group ("low-risk passenger", "normal passenger" or "high-risk passenger").

A third logit model applies information from postchoice debriefing questions about which attributes the respondents considered in their choices [38]. A relatively large number indicated that they omitted some attribute(s) in their choices, and passenger screening type was the attribute considered least (see Table 2).

While the first and second (standard) logit models implicitly assume that all attributes are considered in all choices, the third logit modelling allows for omission of attributes that are stated to be "unimportant" for respondents (imposing marginal disutility equal to zero). The results of the three different logit models are given in Table 3.

\footnotetext{
${ }^{9}$ This question was also put to passengers in the departure hall of the main Norwegian airport (OSL Gardermoen) in another parallel survey based on self-administered pen-and-paper. In that sample, the weighted average was 3.94 [37].

${ }^{10}$ Sixty-six of the 123 opt-outs stem from 11 respondents who always chose opt-out. We exclude these respondents from the following analysis as they do not provide information about the attribute trade-offs. Taking these respondents into account, the share of opt-outs in Table 1 would be 4.8 rather than 2.3 percent.
} 
In Table 3, $\hat{\beta}_{\text {fatalities }}$ is the coefficient of terrorist fatalities (in Norwegian aviation over the next 25 years) and $\hat{\beta}_{\text {screening }}$ the coefficient of screening type, a dummy that equals 1 for risk-based screening control and 0 for current security screening. In the second model, there are three screening type coefficients created by linking the individual characteristics of self-assignment to expected risk group (three dummies) to the screening type dummy. The screening and fatality coefficients, as well as the time coefficient ( $\left.\hat{\beta}_{\text {time }}\right)$, in minutes, and the cost coefficient $\left(\hat{\beta}_{\text {cost }}\right)$, in NOK, all take negative signs in all three models. The negative sign implies that increased levels lead to utility reduction and a reduced probability of that alternative being chosen. While the negative signs of fatality risk and time-use are obvious, and indeed expected from theory and empirical findings [30], we had no clear a priori expectation on the sign of the coefficient of the passenger screening type.

In a binomial logit, the ratio between coefficients yields an estimate of the marginal rate of substitution - a relative value. Dividing other coefficients by the cost coefficients yields a monetized part-worth of an attribute.
Multiplying the estimated time/cost coefficient ratio by 60 , we get the implicit value of travel time saving in air travel of slightly more than EUR 40 per hour in all three models, which is quite high compared to valuations in Norwegian road transport context [34]. The implicit valuation per air travel of reducing the number of terrorist fatalities by one, over 25 years, is approximately EUR 5.30 in the two models not allowing for attribute elimination. Regarding terrorist fatality risk per air trip, from the choice scenario we have 15 fatalities in 25 years or 0.6 per year, and there are 20 million trips annually at the main airport in Norway [8]. Thus, the implicit risk level is c. 3/100 mill., which yields a "very high" implicit valuation of a statistical life, estimated as the fatalities/cost coefficient ratio (EUR 5.30) divided by the risk, i.e. c. EUR 177 mill. ${ }^{11}$ In the third model, allowing for attribute elimination, the implicit valuation per air travel of reducing the number of terrorist fatalities is even higher.

The estimated valuation, per trip, of not changing screening type from the current uniform regime to a new risk-based screening control regime is approximately

Table 1. Attribute balance and choice behaviour.

\begin{tabular}{|c|c|c|c|c|}
\hline & & & Attribute & \\
\hline & Cost & Time & Terrorist fatalities & Passenger screening type \\
\hline Alternatives with best level on attribute & $50.0 \%$ & $46.6 \%$ & $64.3 \%$ & $54.8 \%$ (current) \\
\hline Alternatives with worst level on attribute & $47.7 \%$ & $51.1 \%$ & $33.4 \%$ & $42.9 \%$ (new) \\
\hline Don’t know (opt-out) & $2.3 \%$ & $2.3 \%$ & $2.3 \%$ & $2.3 \%$ \\
\hline Total & $100 \%$ & $100 \%$ & $100 \%$ & $100 \%$ \\
\hline
\end{tabular}

Table 2. Stated attention to attributes in choices (from post-choice debriefing).

\begin{tabular}{|c|c|c|c|c|}
\hline & \multirow[b]{2}{*}{ Cost } & \multicolumn{3}{|c|}{ Attribute } \\
\hline & & Time & Terrorist fatalities & Passenger screening type \\
\hline Ticked (if paid attention) & $61.9 \%$ & $59.8 \%$ & $51.1 \%$ & $33.8 \%$ \\
\hline \multicolumn{5}{|c|}{$\begin{array}{l}\text { "The high valuation estimates from our logit models may to some extent be driven by an underestimated cost coefficient. With this in mind, we can } \\
\text { calculate non-monetized part-worth between the other attributes than cost. If we look at the trade-off between "screening type" and "terrorist fatality } \\
\text { change", applying the first model not allowing for attribute elimination, we get a ratio of } 2.55 \text {, which can be interpreted as the requirement from the } \\
\text { average citizen on the risk effect that a new risk-based screening control must have to be accepted. In other words, it must contribute to the reduction } \\
\text { of expected terrorist fatalities against Norwegian air transport by } 2.55 \text { (from } 15 \text { to } 12.45 \text { ) over the next } 25 \text { years. Likewise, if we look at the trade-off } \\
\text { between "screening type" and "time use change", we get a ratio of } 19.8 \text {. Thus, a new risk-based screening control must contribute to the reduction of } \\
\text { expected average time-use per trip by nearly } 20 \text { minutes to be accepted. }\end{array}$} \\
\hline
\end{tabular}


Table 3. Binomial logit models ${ }^{\mathrm{a}}$.

\begin{tabular}{|c|c|c|c|}
\hline \multirow[b]{2}{*}{ Variable } & \multicolumn{3}{|c|}{ Type of model } \\
\hline & $\begin{array}{l}\text { Not allowing for } \\
\text { attribute elimination }\end{array}$ & $\begin{array}{c}\text { Not allowing for attribute elimination/Screening preference with } \\
\text { respect to self-assignment to expected risk group }\end{array}$ & $\begin{array}{l}\text { Allowing for attribute } \\
\text { elimination }\end{array}$ \\
\hline$\hat{\beta}_{A S C}{ }^{\mathrm{b}}$ & -0.0164 & -0.0160 & -0.0154 \\
\hline std. error & 0.0445 & 0.0447 & 0.0479 \\
\hline$t$ test & -0.37 & -0.36 & -0.32 \\
\hline$\hat{\beta}_{\cos t}{ }^{\mathrm{c}}$ & -0.00260 & -0.00261 & -0.00402 \\
\hline std. error & 0.000262 & 0.000263 & 0.000366 \\
\hline$t$ test & -9.93 & -9.93 & -10.97 \\
\hline$\hat{\beta}_{\text {screening }}$ & -0.317 & & -0.311 \\
\hline std. error & 0.0453 & & 0.0850 \\
\hline$t$ test & -6.99 & & -3.66 \\
\hline$\hat{\beta}_{\text {screening }}^{\text {low risk }}$ & & -0.164 & \\
\hline std. error & & 0.0580 & \\
\hline$t$ test & & -2.82 & \\
\hline$\hat{\beta}_{\text {screening }}^{\text {normal }}$ & & -0.541 & \\
\hline std. error & & 0.0721 & \\
\hline$t$ test & & -7.50 & \\
\hline$\hat{\beta}_{\text {screening }}^{\text {high risk }}$ & & -1.03 & \\
\hline std. error & & 0.720 & \\
\hline$t$ test & & -1.43 & \\
\hline$\hat{\beta}_{\text {fatalities }}$ & -0.124 & -0.125 & -0.231 \\
\hline std. error & 0.00686 & 0.00690 & 0.0110 \\
\hline$t$ test & -18.12 & -18.15 & -21.04 \\
\hline$\hat{\beta}_{\text {time }}$ & -0.124 & -0.125 & -0.231 \\
\hline std. error & 0.00686 & 0.00690 & 0.0110 \\
\hline$t$ test & -18.12 & -18.15 & -21.04 \\
\hline Log likelihood - null & -1690.59 & -1690.59 & -1690.59 \\
\hline Log likelihood - final & -1466.74 & -1457.68 & -1301.34 \\
\hline Likelihood ratio test & 447.69 & 465.81 & 778.495 \\
\hline $\begin{array}{l}\text { Adj. rho square } \\
\text { (McFadden) }\end{array}$ & 0.129 & 0.134 & 0.227 \\
\hline No. of obs. (choices) & 2439 & 2439 & 2439 \\
\hline No. of respondents ${ }^{\mathrm{d}}$ & 421 & 421 & 421 \\
\hline
\end{tabular}

a. Estimated in BIOGEME [39]; b. The coefficient $\beta_{\mathrm{ASC}}$ is the coefficient of an alternative-specific constant; c. Costs are given in Norwegian kroner (NOK). We apply an exchange rate of NOK/EUR equal to 9, which is close to the average over the period of the survey, in the end of June and the beginning of July, in 2009 (Norges Bank, http://www.norges-bank.no/default__ 106.aspx). d. 11 respondents fell out because they always chose the opt-out.

EUR 13.50 in the first model. This must be considered a "very high" valuation of avoiding risk-based screeningcontrol. The second model shows that the preference for screening type clearly depends on the self-assignment to expected risk group. Those who assign themselves to the "low-risk passenger" group attach a significantly lower value to avoiding the risk-based security system com- pared to those who assign themselves to the "normal passenger" group; with a confidence interval of [EUR 2, EUR 12] for the "low-risk passenger" group vs. [EUR 16, EUR 30] for the "normal passenger" group. For the very few who assign themselves to the "high-risk passenger" group the valuation of avoiding risk-based screening is even higher, but the coefficient is not significant, yield- 
ing a very wide confidence interval of [EUR -18, EUR 106]. The third model (in Table 3), allowing for attribute elimination, elucidates the effect of two-thirds of the respondents not considering the "passenger screening type" attribute (as displayed in Table 2). ${ }^{12}$

As regards the goodness-of-fit of the three models (the likelihood ratio test, adj. rho square), we observe an improvement from the first to the second, splitting the screening preference with respect to self-assignment to expected risk group. We observe an even stronger improvement in the third model, allowing for attribute elimination.

\section{Discussion}

In this paper, we have presented a simple choice experiment where a sample of the Norwegian population chose between hypothetical alternatives that differed in security regime, in time-use, in cost and in impact on expected number of fatalities due to terrorist attacks on air transport. In a standard logit modelling of this four-attribute choice experiment, both time-use and fatalities had expected negative signs, and a change to risk-based screening also obtained a negative sign. The implicit (negative) value of risk-based screening, dividing its coefficient by the cost coefficient, was considerable. Both biometric cards and body scanning of high-risk passengers might be considered intrusive [14]. Even though changes in screening type and screening intensity may affect terrorist risk, some people may still not want to sacrifice civil liberties to reduce it [7]. Clearly, the assessment of civil liberties against security may differ between nationalities, depending inter alia on the terror risk $[25,40]$. In Norway, the risk of terror can be considered as relatively low [8].

Unfortunately the choice experiment in our study could not be pivoted onto actual air travel. Thus, the respondents might to some extent have regarded the choice as purely hypothetical. On the other hand, all attributes in the choice experiment had the expected signs and were statistically significant. The implicit estimates of the value of a statistical life (VSL) were "very high", at least one order of magnitude higher than recent VSL estimates from Scandinavia [33,34]. However, VSL might be high er in air transport than in other forms of transport [41]; VSL is affected by the context and might be higher in a terrorist context than in an accident context [22], thereby yielding a "dread premium" [42]. Still, we believe that the very low underlying risk per trip is the most important

\footnotetext{
${ }^{12}$ The logit models also included an alternative-specific constant, $\beta_{\mathrm{ASC}}$, for the purpose of testing for any systematic choice of either alternative $k$ or alternative $l$, either of which would indicate lack of utility balance or effort minimization by the respondents (e.g. by always picking the left alternative). Yet, the ASC coefficient is insignificantly different from zero and low in absolute numbers in all three models.
}

reason for inflating the VSL $[43,44] .^{13}$

Apparently, preferences are heterogeneous for screening control type. A share of the respondents chose the alternative with current uniform screening control before the alternative with new risk-based screening control, even though the former implied considerably higher costs. The resulting implicit valuation of avoiding risk-based screening for the sample was "very high". When taking into account that a proportion of the respondents did not weigh screening control type in their choices (notwithstanding self-assignment to risk group), the implicit valuation was reduced considerably. However, there is the possibility of inconsistency between choices and postchoice statements of which attribute they consider in their choices. Another modelling specification showed that the preference for risk-based screening depends on people's expectations about which risk group they belong to. Those assigning themselves to the "low-risk passenger" group are least negative to risk-based screening control. ${ }^{14}$

\section{Conclusions}

For Norwegians at existing perceived levels of terrorist risk against transport our results indicate that protecting privacy is preferred to a new risk-based screening system even though this is considered as potentially preventing terrorist fatalities. These results may to some extent depend on the framing of the choice experiment in our survey. The preferences against more intrusive screening control at airports are significantly stronger for those persons who do not assign themselves to a low-risk passenger category.

The advantage of choice experiments is the combined assessment of threats/risks, countermeasures and direct/ indirect effects such as time-use and costs. The particular threat or risk can be put into a relevant decision context by this - in our case related to air travel decisions yielding useful input into assessing the public's opinion and the economic efficiency of security policies $[16,17]$.

Several potential developments of our choice experi-

\footnotetext{
${ }^{13}$ In a different type of policy context stated-choice study from the US, trade-offs for homeland security policies were assessed, focussing on "the willingness to pay for anti-missile laser jamming countermeasures mounted on commercial aircraft" [18]. Also in this study an implicit VSL estimate would be higher than the official VSL, due to the low underlying risk level. The estimated willingness to pay for anti-missile laser jamming was between USD 100 and USD 220 annually per household.

${ }^{14}$ Parallel surveying of air travellers within our project also indicated divided opinions in relation to screening control [37]. Actually, the logit model specification for the analysis of our data (e.g. allowing or not for attribute attendance in the logit modelling) would affect the outcome of a cost-benefit analysis of risk-based screening control given that screening control type really affects terrorist risk and that risk-based screening control reduces time-use at airports [8].
} 
ment approach are relevant: pivoting in individuals' specific travel behaviour and exploration of scenario framings could provide validation of our results. Pivoting hypothetical changes in an actual reference trip by air would increase realism and relevance of the scenario, and probably incite more attention to time-use and travel costs. Furthermore, both the selected terrorist risk presentation and the presentation of risk-based screening control may affect choices. Finally, the stated choice could be cast as a policy scenario $[7,18]$, rather than an air travel scenario, but we leave these and other issues for future research.

\section{Acknowledgements}

This study was funded by the Research Council of Norway through the project "Coping with the new risks: Understanding, organization and economics" (186774), under the programme "Risk and Safety in Transport" (RISIT). Data were collected in cooperation with the project "Valuations in transport", supported by the Norwegian Public Roads Administration, the Norwegian National Rail Administration, the Norwegian Coastal Administration and Avinor AS (operator of the Norwegian airport network). We also thank Juned Akhtar for his contribution. All remaining errors and omissions are entirely our own responsibility.

\section{References}

[1] D. Lyon, "Airport Screening, Surveillance and Social Sorting: Canadian Responses to 9/11 in Context," Canadian Journal of Criminology and Criminal Justice, Vol. 48, No. 3, 2006, pp. 397-411.

[2] M. B. Salter, "SeMS and Sensibility: Security Management Systems and the Management of Risk in the Canadian Air Transport Security Authority," Journal of Air Transport Management, Vol. 13, No. 6, 2007, pp. 389-398. doi:10.1016/j.jairtraman.2007.07.004

[3] R. W. Poole, Jr., "Toward risk-based aviation security policy?" Discussion Paper No. 2008-23, prepared for the OECD/ITF Round Table of 11-12 December 2008 on Security, Risk Perception and Cost-Benefit Analysis, Organisation for Economic Cooperation and Development, Paris, 2008.

[4] A. Ghobrial and W. A. Irvin, "Combating Air Terrorism: Some Implications to the Aviation Industry," Journal of Air Transportation, Vol. 9, No. 3, 2004, pp. 67-86.

[5] P. Seidenstat, "Terrorism, Airport Security, and the Private Sector," Review of Policy Research, Vol. 21, No. 3, 2004, pp. 275-291. doi:10.1111/j.1541-1338.2004.00075.x

[6] G. Blalock, V. Kadiyali and D. H. Simon, "The Impact of Post-9/11 Airport Security Measures on the Demand for Air Travel," Journal of Law and Economics, Vol. 50, No.

\section{4, 2007, pp. 731-755. doi:10.1086/519816}

[7] V. K. Viscusi and R. J. Zeckhauser, "Sacrificing Civil Liberties to Reduce Terrorism Risks," Journal of Risk and Uncertainty, Vol. 26, No. 2-3, 2003, pp. 99-120. doi:10.1023/A:1024111622266

[8] J. Akhtar, T. Bjørnskau and K. Veisten, “Assessing Security Measures Reducing Terrorist Risk: Inverse Expost Cost-Benefit and Cost-Effectiveness Analyses of Norwegian Airports and Seaports," Journal of Transportation Security, Vol. 3, No. 3, 2010, pp. 179-195. doi:10.1007/s12198-010-0046-Z

[9] L. A. McLay, S. H. Jacobson and J. E. Kobza, "The Tradeoff Between Technology and Prescreening Intelligence in Checked Baggage Screening for Aviation Security," Journal of Transportation Security, Vol. 1, No. 2, 2008, pp. 107-126. doi:10.1007/s12198-007-0010-8

[10] R. W. Poole Jr. and G. Passantino, "A risk-based airport security policy," Policy Study No. 308, Reason Public Policy Institute, Reason Foundation, Los Angeles, 2003.

[11] R. W. Poole Jr., “Airport Security: Time for a New Model," Policy Study No. 340, Reason Public Policy Institute, Reason Foundation, Los Angeles, 2006.

[12] B. S. Frey, S. Luechinger and A. Stutzer, "Calculating Tragedy: Assessing the Costs of Terrorism," CESifo Working Paper No. 1341, Center for Economic Studies, Ifo Institute for Economic Research e.V., University of Munich, Munich, November 2004.

[13] W. Peissl, "Surveillance and Security: A Dodgy Relationship," Journal of Contingencies and Crisis Management, Vol. 11, No. 1, 2003, pp. 19-24(6).

[14] P. H. O'Neil, "Complexity and Counterterrorism: Thinking about Biometrics," Studies in Conflict and Terrorism, Vol. 28, 2005, pp. 547-566. doi:10.1080/10576100591008962

[15] T. Ojanen, "Terrorist Profiling: Human Rights Concerns," Critical Studies on Terrorism, Vol. 3, No. 2, 2010, pp. 295-312. doi:10.1080/17539153.2010.491343

[16] N. Robinson, D. Potoglou, C. Kim, P. Burge and R. Warnes, "Security, at what cost? Quantifying people's trade-offs across liberty, privacy and security,” Technical Report, RAND Europe, Cambridge, 2010.

[17] D. Potoglou, N. Robinson, C. W. Kim, P. Burge and R. Warnes, 'Quantifying Individuals' Trade-offs Between Privacy, Liberty and Security: The Case of Rail Travel in UK," Transportation Research Part A, Vol. 44, No. 3, 2010, pp. 169-181. doi:10.1016/j.tra.2009.12.006

[18] V. K. Smith, C. Mansfield and L. Clayton, "Valuing a Homeland Security Policy: Countermeasures for the Threats from Shoulder Mounted Missiles," Journal of Risk and Uncertainty, Vol. 38, No. 3, 2009, pp. 215-243. doi:10.1007/s11166-009-9069-x

[19] N. O. Keohane and R. J. Zeckhauser, "The Ecology of Terror Defense," Journal of Risk and Uncertainty, Vol. 26, No. 2-3, 2003, pp. 201-229. doi:10.1023/A:1024167124083

[20] M. G. Stewart and J. Mueller, “Assessing the Risks, 
Costs and Benefits of United States Aviation Security Measures," Research Report No. 267.04.08, Centre for Infrastructure Performance and Reliability, University of Newcastle, Newcastle, 2004.

[21] M. W. Jones-Lee, "The Value of Changes in the ProbAbility of Death or Injury," Journal of Political Economy, Vol. 82, No. 4, 1974, pp. 835-849. doi: $10.1086 / 260238$

[22] L. A. Robinson, "How Federal Agencies Value Mortality Risk," Review of Environmental Economics and Policy, in press.

[23] T. Brück and B.-A. Wickström, "The Economic Consequences of Terror: Guest Editors' Introduction," European Journal of Political Economy, Vol. 20, No. 2, 2004, pp. 293-300.

[24] B. S. Frey and S. Luechinger, "Measuring Terrorism," In: A. Marciano and J.-M. Josselin, Eds., Law and the State: A Political Economy Approach, Edward Elgar Publishing Ltd., Cheltenham, 2005, pp. 142-181.

[25] J. Rosen, "The Naked Crowd: Balancing Privacy and Security in an Age of Terror," Arizona Law Review, Vol. 46, 2004, pp. 607-619.

[26] N. Garoupa, J. Klick and F. Parisi, "A Law and Economics Perspective on Terrorism," Public Choice, Vol. 128, No. 1-2, 2006, pp. 147-168. doi:10.1007/s11127-006-9058-4

[27] I. J. Bateman, R. T. Carson, B. Day, W. M. Hanemann, N. Hanley, T. Hett, M. Jones-Lee, G. Loomes, S. Mourato, E. Ozdemerioglu, D. W. Pearce, R. Sugden and J. Swanson, "Economic Valuation with Stated Preference Techniques: A Manual," Edward Elgar, Ltd., Cheltenham, 2002.

[28] D. McFadden, "Conditional Logit Analysis of Qualitative Choice Behaviour," In: P. Zarembka, Ed., Frontiers in Econometrics, Academic Press, New York, Vol. 1, No. 2, 1974, pp. 105-142.

[29] M. Ben-Akiva and S. R. Lerman, "Discrete Choice Analysis," MIT Press, Cambridge, 1985.

[30] L. I. Rizzi and J. de D. Ortúzar, "Stated Preference in the Valuation of Interurban Road Safety," Accident Analysis and Prevention, Vol. 35, No. 1, 2003, 9-22. doi:10.1016/S0001-4575(01)00082-3

[31] S. Bhattacharya, "The Value of Mortality Risk Reductions in Delhi, India," Ph.D. dissertation, Faculty of the Graduate School, University of Maryland, Maryland, 2006.

[32] W. K. Viscusi and J. E. Aldy, "The Value of a Statistical life: A Critical Review of Market Estimates throughout the World," Journal of Risk and Uncertainty, Vol. 27, No. 1, 2003, pp. 5-76. doi:10.1023/A:1025598106257
[33] M. Svensson, "What is a Life Worth? Methodological Issues in Estimating the Value of a Statistical Life," Ph.D. dissertation, Örebro Studies in Economics, Örebro University, Örebro, 2007.

[34] H. Samstad, F. Ramjerdi, K. Veisten, S. Navrud, K. Magnussen, S. Flügel, M. Killi, A. H. Halse, R. Elvik and O. San Martín, "Values of Time, Safety and Environment in Norwegian Passenger Transport," ТØI Report 1053, Institute of Transport Economics (TØI), Oslo, 2010.

[35] G. LaFree, L. Dugan, H. V. Fogg and J. Scott, "Building a Global Terrorism Database," Report to U.S. Department of Justice (Doc. No. 214260), University of Maryland, Baltimore, 27 April 2006.

[36] PGIS, "Global terrorism database 1998-2004. GTD2, Codebook, Draft1.0," Pinkerton Global Intelligence Services, Washington DC, May 2007.

[37] A. Amundsen, "Nordmenn og svenskers syn på per- sonvern, sikkerhetstiltak og terrortrusselen: undersøk- else blant passasjerer på fly, ferje og tog," TØI Working Paper SM-2091, Institute of Transport Economics (TØI), Oslo, 2009.

[38] D. A. Hensher, J. M. Rose and W. H. Greene, "The Implications of Willingness to Pay of Respondents Ig- noring Specific Attributes," Transportation, Vol. 32, No. 3, 2005, pp. 203-222. doi:10.1007/s11116-004-7613-8

[39] M. Bierlaire, "BIOGEME: A Free Package for the Estimation of Discrete Choice Models," Proceedings of the 3rd Swiss Transportation Research Conference, Ascona, 19-21 March 2003, pp. 24.

[40] J. G. Leo and J. P. Lawler, "A Study of Passenger Perception and Sensitivity to Airport Backscatter X-ray Technologies," International Business \& Economics Research Journal, Vol. 6, No. 7, 2007, pp. 11-18.

[41] F. Carlsson, O. Johansson-Stenman and P. Martinsson, "Is Transport Safety More Valuable in the Air?" Journal of Risk and Uncertainty, Vol. 28, No. 2, 2004, pp. 147-163. doi:10.1023/B:RISK.0000016141.88127.7c

[42] S. M. Chilton, M. W. Jones-Lee, F. Kiraly, H. Metcalf and W. Pang, "Dread Risk," Journal of Risk and Uncertainty, Vol. 33, No. 3, 2006, pp. 165-182. doi:10.1007/s11166-006-0483-Z

[43] J. K. Hammitt, "Valuing Mortality Risk: Theory and Practice," Environmental Science and Technology, Vol. 34, No. 8, 2000, pp. 1396-1400. doi:10.1021/es990733n

[44] R. T. Carson, N. E. Flores and N. F. Meade, "Contingent Valuation: Controversies and Evidence," Environmental and Resource Economics, Vol. 19, No. 2, 2001, pp. 173-210. 